\title{
Caveolin- 1 is required for TGF- $\beta$-induced transactivation of the EGF receptor pathway in hepatocytes through the activation of the metalloprotease TACE/ADAM17
}

\author{
J Moreno-Càceres ${ }^{1}$, L Caja ${ }^{1}$, J Mainez ${ }^{2}$, R Mayoral ${ }^{3,4}$, P Martín-Sanz ${ }^{4,5}$, R Moreno-Vicente ${ }^{6}$, MÁ del Pozo ${ }^{6}$, S Dooley $^{7}$, G Egea $^{2}$ \\ and I Fabregat ${ }^{\star, 1,8}$
}

Transforming growth factor-beta (TGF- $\beta$ ) plays a dual role in hepatocytes, inducing both pro- and anti-apoptotic responses, whose balance decides cell fate. Survival signals are mediated by the epidermal growth factor receptor (EGFR) pathway, which is activated by TGF- $\beta$ in these cells. Caveolin- 1 (Cav1) is a structural protein of caveolae linked to TGF- $\beta$ receptors trafficking and signaling. Previous results have indicated that in hepatocytes, Cav1 is required for TGF- $\beta$-induced anti-apoptotic signals, but the molecular mechanism is not fully understood yet. In this work, we show that immortalized Cav1 ${ }^{-l-}$ hepatocytes were more sensitive to the pro-apoptotic effects induced by TGF- $\beta$, showing a higher activation of caspase-3, higher decrease in cell viability and prolonged increase through time of intracellular reactive oxygen species (ROS). These results were coincident with attenuation of TGF- $\beta$-induced survival signals in Cav1 ${ }^{-l-}$ hepatocytes, such as AKT and ERK1/2 phosphorylation and NF $k$-B activation. Transactivation of the EGFR pathway by TGF- $\beta$ was impaired in Cav1 ${ }^{-1-}$ hepatocytes, which correlated with lack of activation of TACE/ADAM17, the metalloprotease responsible for the shedding of EGFR ligands. Reconstitution of Cav1 in Cav1 ${ }^{-I-}$ hepatocytes rescued wild-type phenotype features, both in terms of EGFR transactivation and TACE/ADAM17 activation. TACE/ADAM17 was localized in detergent-resistant membrane (DRM) fractions in Cav1 ${ }^{+/+}$cells, which was not the case in Cav1 $1^{-I-}$ cells. Disorganization of lipid rafts after treatment with cholesterol-binding agents caused loss of TACE/ADAM17 activation after TGF- $\beta$ treatment. In conclusion, in hepatocytes, Cav1 is required for TGF- $\beta$-mediated activation of the metalloprotease TACE/ADAM17 that is responsible for shedding of EGFR ligands and activation of the EGFR pathway, which counteracts the TGF- $\beta$ pro-apoptotic effects. Therefore, Cav1 contributes to the pro-tumorigenic effects of TGF- $\beta$ in liver cancer cells.

Cell Death and Disease (2014) 5, e1326; doi:10.1038/cddis.2014.294; published online 17 July 2014

The transforming growth factor-beta (TGF- $\beta$ ) belongs to a family of polypeptide factors, whose cytostatic and apoptotic functions help restrain the growth of mammalian cells. However, paradoxically, TGF- $\beta$ also modulates processes such as cell invasion, immune regulation and microenvironment modification, which cancer cells may exploit to their advantage. ${ }^{1}$ Indeed, a better knowledge about the mechanistic basis and clinical relevance of TGF- $\beta$ is required for a better understanding of the complexity and therapeutic potential of this pathway. In hepatocytes, TGF- $\beta$ induces both pro- and anti-apoptotic signals, whose balance decides cell fate. $^{2}$ Those hepatocytes that survive to TGF- $\beta$-mediated apoptosis induce an epithelial-mesenchymal transition (EMT) process, which confers migratory properties and apoptosis resistance. ${ }^{3}$ The anti-apoptotic signals are at least partially mediated by the epidermal growth factor receptor (EGFR) pathway, which is transactivated by TGF- $\beta$ through a mechanism that involves upregulation of the EGFR ligands and activation of the metalloprotease TACE/ADAM17 responsible for their shedding. ${ }^{4,5}$

Many efforts have been done in the recent years for a better understanding of spatial requirements on TGF- $\beta$ signaling, including endocytic TGF- $\beta$ receptors trafficking. Strong pieces of evidence support that TGF- $\beta$ receptors can be located both in clathrin-coated pits and caveolin/cholesterol-enriched lipid rafts. $^{6,7}$ A pioneer study from Di Guglielmo et al. ${ }^{8}$ proposed that Smad2 phosphorylation would require clathrin-dependent endocytosis, whereas TGF- $\beta$ receptors internalization via

\footnotetext{
${ }^{1}$ Bellvitge Biomedical Research Institute (IDIBELL), Barcelona, Spain; ${ }^{2}$ Department of Cell Biology, Immunology and Neuroscience, School of Medicine IDIBAPSUniversity of Barcelona, Barcelona, Spain; ${ }^{3}$ Department of Medicine, University of California, San Diego, La Jolla, CA, USA; ${ }^{4}$ Networked Biomedical Research Center on Hepatic and Digestive Diseases (CIBERehd), Madrid, Spain; ${ }^{5}$ Alberto Sols Biomedical Research Institute, CSIC-UAM, Madrid, Spain; ${ }^{6}$ Integrin Signaling Laboratory, National Center for Cardiovascular Research (CNIC), Madrid, Spain; ${ }^{7}$ Molecular Hepatology section, Department of Medicine II, Medical Faculty Mannheim, University of Heidelberg, Mannheim, Germany and ${ }^{8}$ Department of Physiological Sciences II, University of Barcelona, Barcelona, Spain

${ }^{*}$ Corresponding author: I Fabregat, Bellvitge Biomedical Research Institute (IDIBELL). Gran Via de L'Hospitalet, 199. 08908 L'Hospitalet de Llobregat, Barcelona, Spain. Tel: +34 93 2607828; Fax: +34 93 2607426; E-mail: ifabregat@idibell.cat

Abbreviations: Cav1, caveolin-1; DRMs, detergent-resistant membranes; EGF, epidermal growth factor; EGFR, epidermal growth factor receptor; HB-EGF, heparinbinding EGF-like growth factor; M $\beta$ C, methyl- $\beta$-cyclodextrin; NOX, NADPH oxidase; PI-3K, phospho-inositol-3-kinase; ROS, reactive oxygen species; TGF- $\alpha$, transforming growth factor-alpha; TGF- $\beta$, transforming growth factor-beta

Received 18.2.14; revised 14.5.14; accepted 05.6.14; Edited by D Vucic
} 
caveolae/lipid rafts would inhibit its signaling. From then, different studies have suggested that the endocytic pathways' role on TGF- $\beta$ signaling depend on the cell type and a general rule about the role of endocytosis in TGF- $\beta$ signaling is not well understood yet. ${ }^{9}$ In hepatocytes, Smad activation is in a large extent accomplished on the hepatocyte plasma membrane in an AP-2 complex-dependent manner, being unnecessary the formation of clathrin-coated pits. ${ }^{10}$ In contrast, the non-Smad/ AKT pathway activation requires caveolin-1 (Cav1)-dependent endocytosis, ${ }^{10}$ which is required for counteracting apoptosis. $^{11}$

Cav1 is required for caveolae formation, which regulates not only endocytosis, but also lipid metabolism and energy homeostasis. ${ }^{12}$ The localization of membrane receptors in the lipid raft pushed to investigate the role of Cav1 in regulating signaling events. In the case of epidermal growth factor (EGF) signaling, it was proposed that non-caveolae-coated pits are involved in the compartmentalization and internalization of the EGFR, although caveolin-rich domains may be required for signaling. ${ }^{13}$ In this line of evidence, different studies revealed an important role for Cav1 in EGFR-induced effects on cell proliferation and migration. ${ }^{14,15}$

In this work, we have examined the role of Cav1 in the antiapoptotic signals induced by TGF- $\beta$ in hepatocytes, postulating that it may be required for TGF- $\beta$-mediated regulation of EGFR signaling. Using different experimental approaches and an immortalized hepatocyte cell line derived from Cav1 ${ }^{-1-}$ mice, we demonstrate that transactivation of the EGFR pathway by TGF- $\beta$ is impaired in $\mathrm{Cav}^{-1}{ }^{-}$hepatocytes. However, Cav1 is not required for the cellular response to EGFR ligands, but is necessary for TGF- $\beta$-mediated activation of the metalloprotease TACE/ADAM17, which is responsible for shedding of EGFR ligands and requires an intact lipid raft domain to be activated by TGF- $\beta$.

\section{Results}

Cav1 deficiency alters the balance between the pro- and anti-apoptotic signals induced by TGF- $\beta$ in hepatocytes. In order to analyze the specific relevance of Cav1 in the response to TGF- $\beta$, we have used an immortalized neonatal hepatocyte cell line obtained from 3-day old Cav1-/animals $^{16}$ (see Materials and Methods section and Supplementary Figure 1a). Cav1 $1^{-1-}$ hepatocytes showed an increased sensitivity to TGF- $\beta$ in terms of cell death, exhibiting a significant higher percentage of non-viable cells when compared with Cav1 $1^{+/+}$cells after $72 \mathrm{~h}$ of treatment (Figures 1a-c). Activation of caspase-3, as a hallmark of apoptosis, showed similar dynamics, being increased in Cav1-deficient hepatocytes when compared with control cells and remained high after $72 \mathrm{~h}$ of TGF- $\beta$ treatment (Figure 1d). Since TGF- $\beta$-induced apoptosis in hepatocytes requires reactive oxygen species (ROS) production mediated by a NADPH oxidase system (NOX4), ${ }^{17}$ we next analyzed intracellular ROS content. Results indicated that the increase in intracellular ROS content was a transient process in Cav1 ${ }^{+/+}$hepatocytes showing a maximum increase after 6-h treatment, decreasing at later times up to levels even lower than those found in the untreated cells. However, in knockout cells (Cav1 $1^{-/-}$), increase in ROS levels were constantly high through all the time (Figure 1e). All these results indicate that apoptotic features induced by TGF- $\beta$ in immortalized neonatal hepatocytes are increased in the absence of Cav1 expression. In fetal and neonatal hepatocytes, TGF- $\beta$ simultaneously induces both pro- and anti-apoptotic signals, whose final balance determines the cell fate. ${ }^{2,4}$ Anti-apoptotic signals include the phosphoinositol-3-kinase (PI-3K)/AKT pathway, MAPK/ERKs and $\mathrm{NF} \kappa-\mathrm{B}$ pathways. Thus, we next examined whether the increased apoptosis observed in Cav1-deficient hepatocytes is caused by impairment in activation of survival signals, triggered by TGF- $\beta$. Western blot analysis showed a significant inhibition of AKT activation and decreased phosphorylation of MAP kinases ERK $1 / 2$ in TGF- $\beta$-treated Cav $1^{-1-}$ cells (Figures $2 \mathrm{a}$ and $\mathrm{b}$ ). In addition, TGF- $\beta$ induced activation of pro-survival $\mathrm{NF}_{\kappa}$-B signaling was also attenuated in Cav1 ${ }^{-1-}$ cells, which showed lower translocation of cytosolic p65 to the nucleus after treatment with the cytokine (Figures 2c and d). Therefore, in the absence of Cav1, the imbalance between pro- and anti-apoptotic regulatory signals finally pushes cells to die.

Cav1 deficiency prevents transactivation of the EGFR pathway by TGF- $\beta$ in hepatocytes. TGF- $\beta$-induced survival signals in hepatocytes and liver tumor cells require transactivation of the EGFR pathway. ${ }^{4,18}$ We hypothesized that EGFR transactivation by TGF- $\beta$ could be perturbed in the absence of Cav1. In Cav1 ${ }^{+/+}$cells, TGF- $\beta$ induced phosphorylation of EGFR, examined both by western blot (Figure 3a) and immunocytochemistry (Figure 3b). Inhibition of the EGFR catalytic activity by the tyrphostin AG1478 showed that EGFR-mediated signaling is necessary to rescue $\mathrm{Cav} 1^{+/+}$hepatocytes from the expected TGF- $\beta$ induced apoptotic fate (Supplementary Figure 2). However, Cav1 ${ }^{-1-}$ cells did not show EGFR phosphorylation in response to TGF- $\beta$ (Figures $3 a$ and $b$ ), and treatment with AG1478 did not alter cell viability (Supplementary Figure 2). Lack of response was not due to differences in EGFR expression, which was similar in $\mathrm{Cav}^{+1+}$ and $\mathrm{Cav}^{-1-}$ cells (Supplementary Figures $1 \mathrm{~b}$ and $\mathrm{c}$ ).

To exclude that the absence of EGFR transactivation by TGF- $\beta$ could be due to a defect acquired during development of the Cav1 knockout mice and not to the mere absence of Cav1, we reconstituted the expression of Cav1 in Cav1 ${ }^{-1-}$ cells. Ectopic expression of Cav1 in the immortalized Cav1 ${ }^{-1-}$ cell line led to a recovery of the wild-type phenotype, with a decreased sensitivity in terms of cell death (Figure 4a) and lower activation of caspase-3 (Figure 4b). It is important to point out that the control cell line ( + IRES-GFP, a control plasmid expressing only GFP) behaved as the parental cell line. Then, activation of AKT and ERK1/2 were examined, evidencing a recovery of AKT phosphorylation and an increase in ERK1/2 phosphorylation in TGF- $\beta$-treated Cav1 ${ }^{-/-}$when expression of Cav1 was restored (Figure 4c). Interestingly, restitution of Cav1 rescued the transactivation of EGFR by TGF- $\beta$ in Cav1 ${ }^{-1-}$ hepatocytes (Figure 4d). In order to confirm the results observed in Cav1 ${ }^{-/}$hepatocytes, we knocked down Cav1 in Cav1 ${ }^{+/+}$hepatocytes using a specific siRNA approach. Downregulation of Cav1 was efficient using 


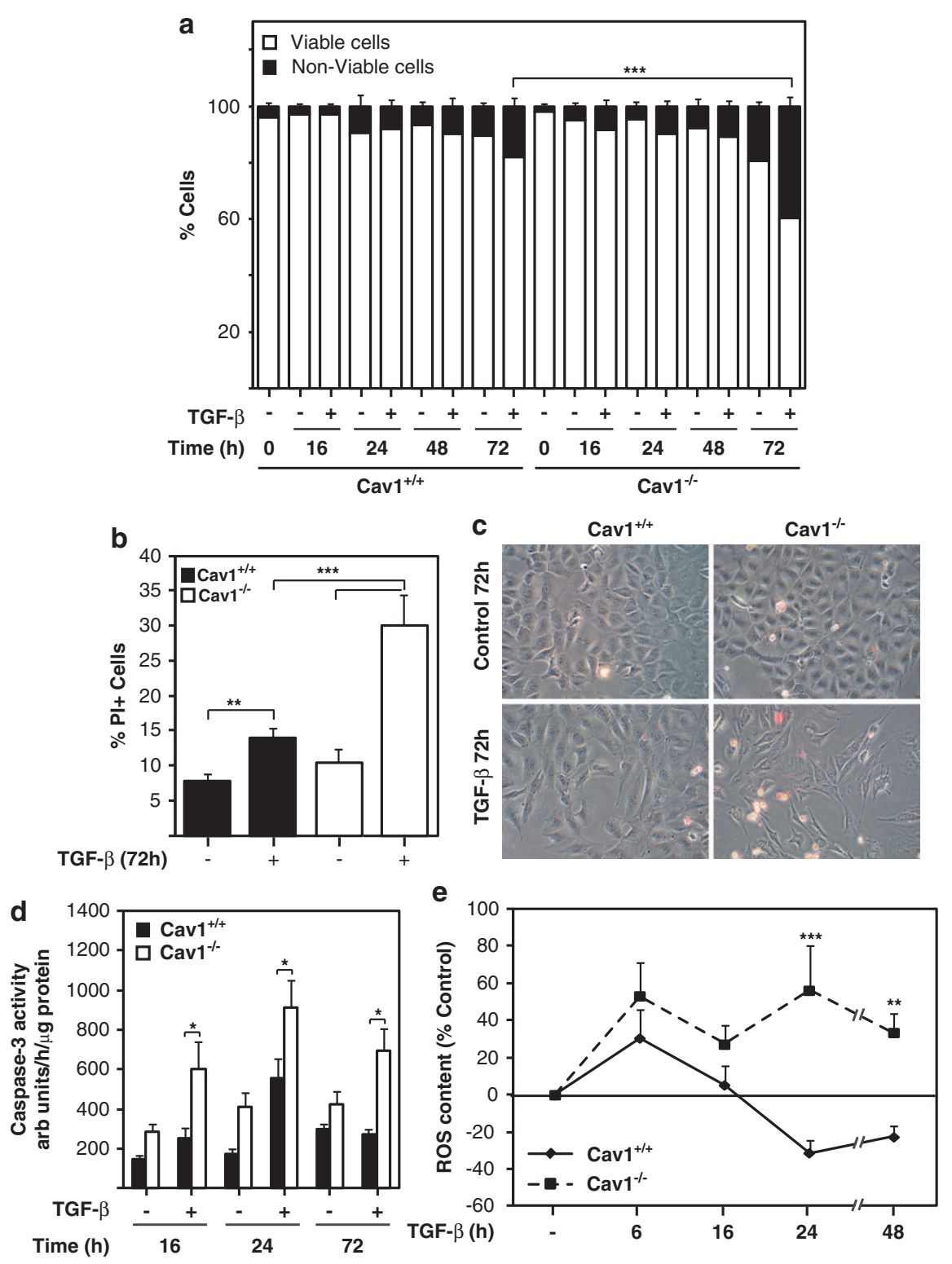

Figure 1 Cav1-deficient hepatocytes are more sensitive to TGF- $\beta$ in terms of apoptosis. Cav1 ${ }^{+/+}$and Cav1 ${ }^{-1-}$ hepatocytes were treated with TGF- $\beta(2 \mathrm{ng} / \mathrm{ml})$ for different times, after previous FBS starvation ( $16 \mathrm{~h}$ ). (a) Cell viability was measured using trypan blue staining, expressed as percentage of viable and non-viable cells $(N=3)$. (b) Cell viability was analyzed by internalization of propidium iodide (PI), expressed as percentage of PI-positive cells $(\mathrm{N}=3)$. (c) Representative PI-staining images taken at $72 \mathrm{~h}$ of treatment. (d) Caspase-3 activity, expressed as arbitrary units per hour and per microgram of protein $(N=3)$. (e) Intracellular ROS production expressed as relative percentage versus untreated cells $(N=3)$. Results expressed as mean \pm S.E.M. Statistical comparison using Student's $t$-test to compare control versus $72-\mathrm{h}$ TGF- $\beta$ treatment in each cell line (b) or two-way ANOVA with Bonferroni post hoc test to compare Cav1 ${ }^{+1+}$ and Cav1 ${ }^{-1-}$ hepatocytes $(\mathbf{a}, \mathbf{b}, \mathbf{d}$ and $\mathbf{e}):{ }^{*} P<0.05 ;{ }^{* \star} P<0.01,{ }^{* \star \star} P<0.001$

two siRNAs (Supplementary Figure 3) and the EGFR phosphorylation after stimulation with TGF- $\beta$ was severely reduced in Cav1-silenced Cav1 ${ }^{+/+}$cells (Supplementary Figure 3). Therefore, we conclude that Cav1 is determinant for the capacity of TGF- $\beta$ to transactivate the EGFR pathway in hepatocytes.

As we observed that the EGFR transactivation was impaired in Cav1 $1^{-1-}$ hepatocytes, a possibility was that Cav1 is required for cell responses to extracellular EGFR ligands. Although we realized that the use of heparin-binding EGF-like growth factor (HB-EGF), as a positive control of
EGFR phophorylation, did not show differences between Cav1 ${ }^{+/+}$and Cav1 ${ }^{-1-}$ cells (Figure 3 ), to fully assess this result, we examined the response to other EGFR ligands such as EGF or transforming growth factor-alpha (TGF- $\alpha$ ). Cav1 deficiency did not prevent the response to any of them in terms of receptor phosphorylation or activation of downstream signals (Figures 5a and b). Furthermore, Cav1 deficiency did not perturb either other cellular responses to EGF receptor ligands, such as cell proliferation (Figure 5c), despite Cav1 ${ }^{-1}$ cells showed higher proliferative ratio in response to FBS, as we had previously described. ${ }^{16}$ 

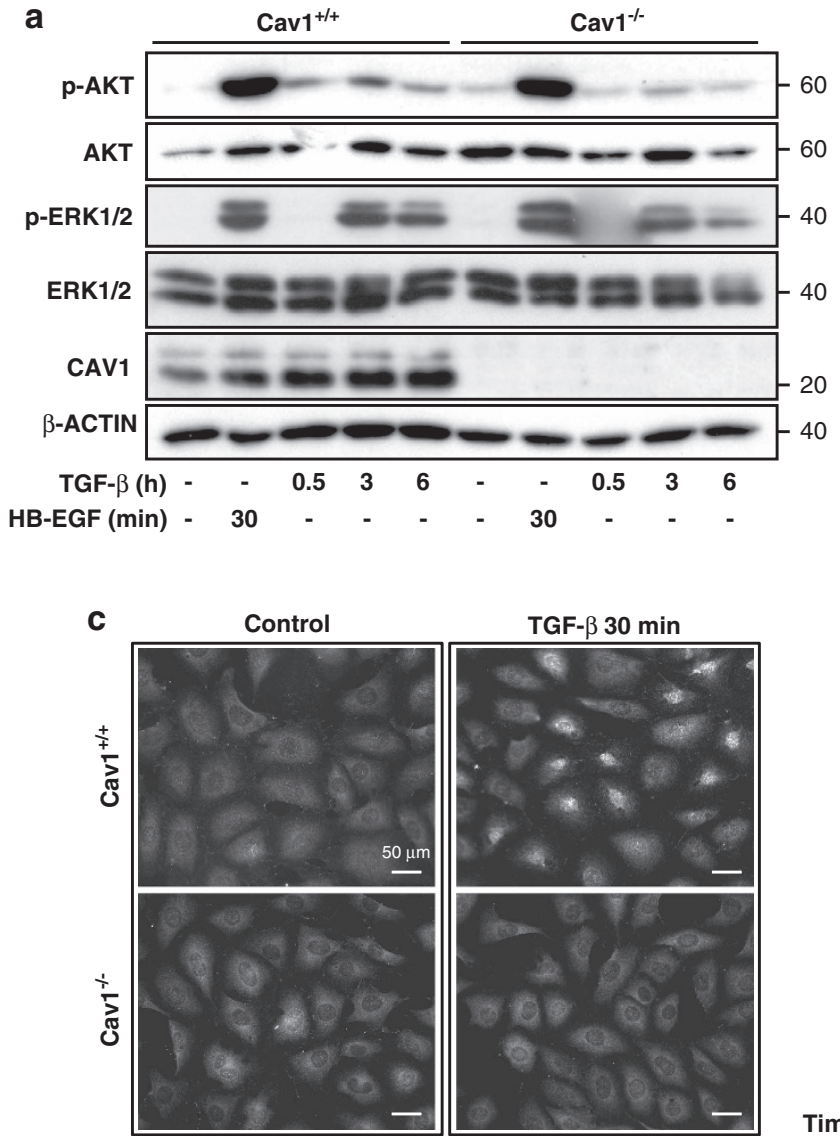

b Cav $1^{+/+} \square$ Cav $1^{-/-}$
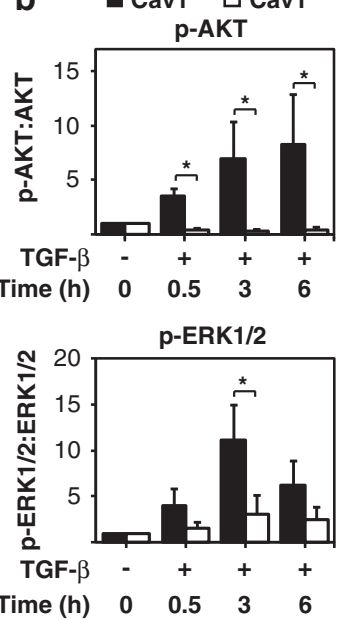

d
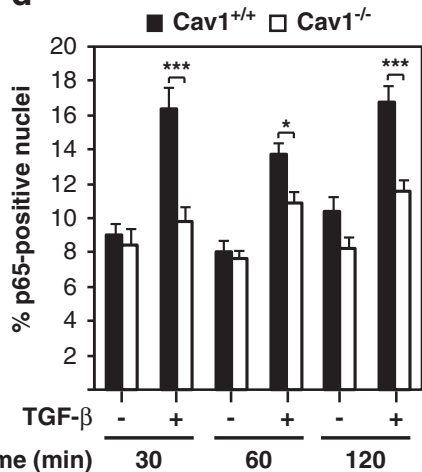

Figure 2 Cav1 is required for TGF- $\beta$-mediated survival signals. Cav1 ${ }^{+/+}$and Cav1 ${ }^{-1}$ cell lines were treated with TGF- $\beta$ (2 $\left.\mathrm{ng} / \mathrm{ml}\right)$ or HB-EGF $(20 \mathrm{ng} / \mathrm{ml})$ at different times, after previous FBS starvation (16h). (a) Western blot of protein extracts; $\beta$-actin as loading control. A representative experiment is shown. (b) Densitometric analysis of the ratio phospho-protein/total protein of the western blots; results are mean \pm S.E.M. of seven independent experiments and expressed as fold induction versus each corresponding control (untreated cells). (c) Representative p65 immunocytochemistry images. (d) Percentage of p65-positive nuclei in at least 10 different fields for experiment $(N=3)$. Statistical comparison using two-way ANOVA with Bonferroni post hoc test as shown in the figure: ${ }^{*} P<0.05 ;{ }^{* \star} P<0.01,{ }^{* \star \star} P<0.001$

\section{Cav1 deficiency impairs TGF- $\beta$-mediated TACE/ADAM17} activity. Hepatocytes express different EGFR ligands, such as HB-EGF, TGF- $\alpha$ or Amphiregulin (Supplementary Figure 4). In order to know whether Cav1 may influence the expression of these ligands, we analyzed their transcript levels by real-time PCR. Results indicated that $\mathrm{Cav1}{ }^{-I_{-}}$ cells do not show decreased expression of EGFR ligands. Even in the case of $\mathrm{TGF}-\alpha$, the levels were higher (Supplementary Figure 4). Indeed, we focused on the shedding of these EGFR ligands, which is required for the binding to the EGFR and activation of this pathway. We previously described that short-term activation of the metalloprotease TACE/ADAM17 by TGF- $\beta$ is required for activation of the EGFR and pro-survival signals in hepatocytes. ${ }^{4}$ Taking this into consideration, here we wondered whether this pathway could be impaired in $\mathrm{Cav1}^{-1-}$ hepatocytes. Analysis of TACE/ADAM17 enzymatic activity using a fluorimetric method demonstrated that Cav1 ${ }^{+/+}$, but not Cav1 ${ }^{-1-}$, hepatocytes responded to TGF- $\beta$ increasing its activity (Figure 6a). Afterward, we studied whether this increase had functional consequences such as a decrease in the shedding of EGFR ligands into the cell media in
TGF- $\beta$-treated Cav1 ${ }^{-1-}$ cells. To this aim, we collected conditioned media from FBS-starved $\mathrm{Cav} 1^{+/+}$and Cav1 ${ }^{-1}$ hepatocytes, either untreated or treated with TGF- $\beta$ to analyze their capacity to phosphorylate the EGFR in control Cav1 ${ }^{+/+}$cells. Conditioned media from Cav1 ${ }^{+/+}$ cells treated with TGF- $\beta$ induced the phosphorylation of the EGFR, in contrast to conditioned media from TGF- $\beta$-treated $\mathrm{Cav1}^{-1-}$ cells (Figure 6b). Long-term treatment of Cav1 ${ }^{+/+}$ hepatocytes with TGF- $\beta$ increased TACE/ADAM17 mRNA levels (Figure 6c), which was dependent on the EGFR pathway, since knockdown of EGFR levels with a specific siRNA attenuated this response (Supplementary Figure 5). Upregulation of TACE by TGF- $\beta$ was not observed in Cav $1^{-1-}$ hepatocytes (Figure 6c). Interestingly, Cav1 restitution in Cav1 ${ }^{-1-}$ hepatocytes led to a full recovery of TACE/ADAM17 activation after TGF- $\beta$ treatment (Figure $6 \mathrm{~d}$ ), which reinforced and confirmed the importance of Cav1 in TACE/ADAM17 activity regulation.

TACE/ADAM17 in lipid rafts is necessary for its TGF- $\beta$-mediated activation. In search for a mechanism that explains how Cav1 may regulate TACE/ADAM17, we 
a

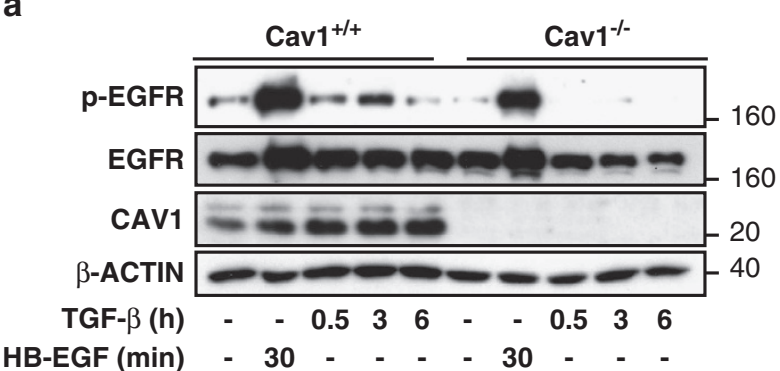

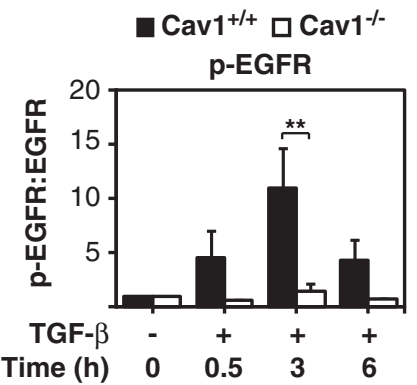

b

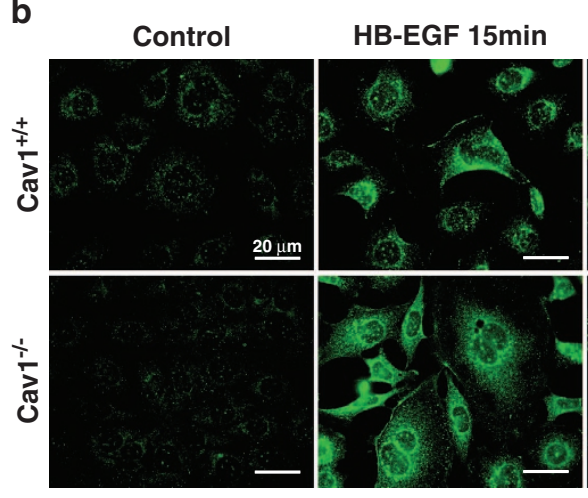

TGF- $\beta 3$ h

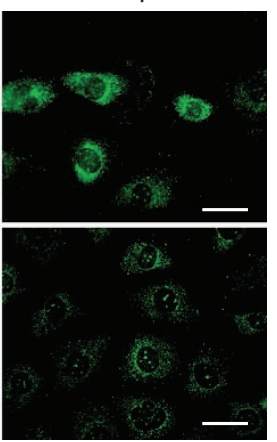

Figure 3 Cav1 deficiency prevents the TGF- $\beta$-mediated EGF receptor transactivation. Cav $1^{+1+}$ and Cav $1^{-1-}$ hepatocytes were treated as shown in Figure 2. (a) (Left panel) western blot of protein extracts; $\beta$-actin as loading control. A representative experiment is shown; (right panel) densitometric analysis of the ratio phospho-EGFR/total EGFR in the western blot; results expressed as fold induction versus each corresponding control (untreated cells), mean \pm S.E.M. of five independent experiments. Statistical comparison using two-way ANOVA with Bonferroni post hoc test: ${ }^{*} P<0.01$. (b) $p$-EGFR immunocytochemistry, HB-EGF used as a positive control of phosphorylation

postulated colocalization of both proteins in lipid rafts of hepatocytes, as recently reported for vascular smooth muscle cells and endothelial cells. ${ }^{19,20}$ Using a sucrose gradient technique to obtain detergent-resistant membranes (DRMs) fractions, we observed that a pool of TACE/ADAM17 is localized in DRMs (identified by the presence of ganglioside GM1) in Cav1 ${ }^{+/+}$hepatocytes (Figure 7a). This was not the case in $\mathrm{Cav1}^{-1-}$ cells, where the amount of TACE/ ADAM17 in DRMs is highly reduced (Figure 7a). This result demonstrates that Cav1 is necessary for TACE/ADAM17 localization in lipid rafts in hepatocytes. We also evaluated whether Cav1-dependent DRMs localization of TACE is regulated by $\mathrm{TGF}-\beta$, particularly in stages when the metalloprotease is more active. We obtained DRMs from cells treated with TGF- $\beta$ and observed an increase of TACE in DRMs in Cav1 ${ }^{+/+}$hepatocytes, but not in Cav1 ${ }^{-/-}$cells (Figure 7a). Finally, as we found that TACE/ADAM17 localization in lipid rafts was increased after TGF- $\beta$ treatment, we examined the effect of lipid raft disruption by cholesterol removal with methyl- $\beta$-cyclodextrin ( $\mathrm{M} \beta \mathrm{C}$ ). $\mathrm{M} \beta \mathrm{C}$ dramatically decreased TGF- $\beta$-induced TACE/ADAM17 activation in Cav1 ${ }^{+1+}$ hepatocytes (Figure $7 \mathrm{~b}$ ), an effect that was reversed by treatment of cells with extracellular cholesterol (Supplementary Figure 6a). Furthermore, other milder cholesterol-binding agents, such as filipin III or nystatin, also inhibited TACE/ADAM17 activation by TGF- $\beta$ (Supplementary Figure 6b). We conclude that Cav1 is required for TACE/ADAM17 activation upon localization to lipid rafts.

\section{Discussion}

The basic elements of the TGF- $\beta$ pathway were detailed at the end of the last century. However, how the intracellular trafficking affects the TGF- $\beta$ signal traveling from the cell membrane to the nucleus, how posttranslational regulation of receptors and Smads regulates signaling and/or how the context determines the cellular response to TGF- $\beta$ are open questions yet. $^{7,21-23}$ In hepatocytes, TGF- $\beta$ induces both proand anti-apoptotic signals, the latter mediated by the EGFR pathway, which is transactivated by TGF- $\beta$ through a mechanism that involves upregulation of the EGFR ligands and activation of the metalloprotease TACE/ADAM17 responsible for their shedding. ${ }^{4,5}$ Cav1, the major component of caveolae, had been also suggested to be necessary for TGF- $\beta$ induction of anti-apoptotic signaling in hepatocytes, although the specific molecular mechanism is not well understood yet. ${ }^{10,11}$ In this work, we demonstrate that in immortalized neonatal mice hepatocytes, Cav1 is required for TGF- $\beta$-mediated transactivation of the EGFR that initiates intracellular signal cascades, such as MAPKs/ERKs and $\mathrm{PI}-3 \mathrm{~K} / \mathrm{AKT}$ pathways, which directly prevent TGF- $\beta$-induced upregulation of the NADPH oxidase NOX4, which is required for its pro-apoptotic response. ${ }^{5}$ Indeed, failure in transactivation of the EGFR pathway increases ROS production and cell death. ${ }^{17}$ The molecular mechanism requires the participation of the TACE/ADAM17, a metalloprotease responsible for the shedding of the EGFR ligands. ${ }^{24}$ Our results indicate that Cav1 determines TACE/ADAM17 localization in lipid rafts in 


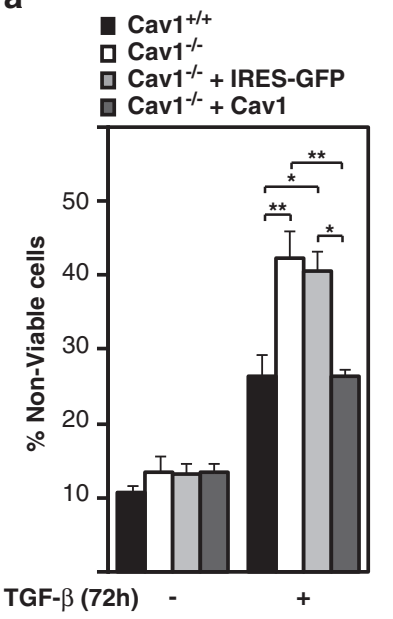

b

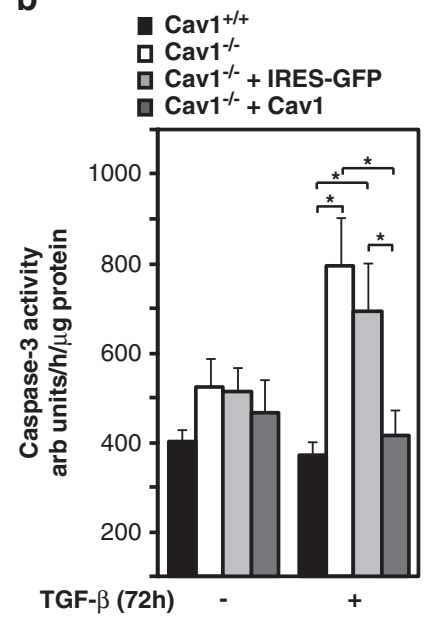

c

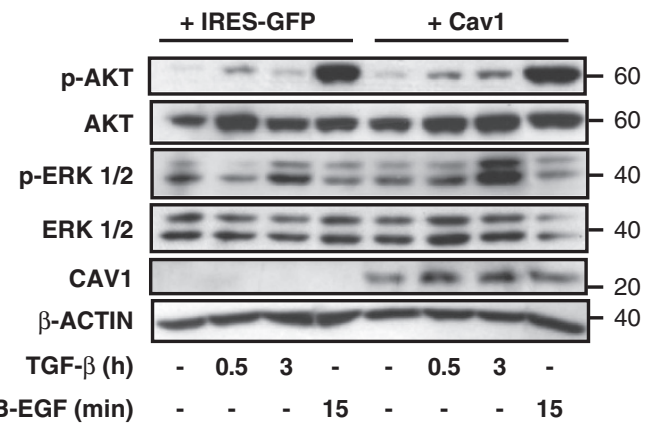

d

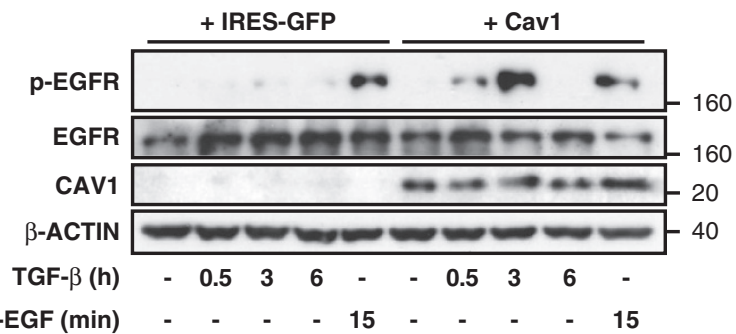

HB-EGF (min) - $\quad-\quad-\quad-15 \quad-\quad-\quad-\quad-15$

Figure 4 Cav1 reconstitution in $\mathrm{Cav} 1^{-/}$hepatocytes recapitulates $\mathrm{Cav} 1^{+/+}$ phenotype in terms of cell death and TGF- $\beta$-mediated EGF receptor transactivation. $\mathrm{Cav1}^{+{ }^{+}+}, \mathrm{Cav1}^{-1^{-}}$, Cav1 $1^{-1-}+$ IRES-GFP and Cav1 ${ }^{-1-}+$ Cav1 cell lines were treated with TGF- $\beta(2 \mathrm{ng} / \mathrm{ml})$ or HB-EGF $(20 \mathrm{ng} / \mathrm{ml})$ at the times shown, after previous FBS starvation (16h). (a) Cell viability was measured using trypan blue staining, expressed as percentage of non-viable cells $(N=3)$. (b) Caspase-3 activity measurement expressed as arbitrary units per hour and per microgram of protein $(N=5)$. Results in $\mathbf{a}$ and $\mathbf{b}$ expressed as mean \pm S.E.M. (c and $\mathbf{d})$ Western blot of protein extracts from Cav1 ${ }^{-1}+$ IRES-GFP and Cav1 $1^{-1}+$ Cav1 cell lines; $\beta$-actin as loading control. A representative experiment is shown. Statistical comparison using two-way ANOVA with Bonferroni post hoc test as shown in the figure: ${ }^{*} P<0.05 ;{ }^{\star \star} P<0.01$

hepatocytes, which in turn is necessary for the TGF- $\beta$ transactivation of the EGFR. Different lines of evidence support our conclusions: (1) in immortalized Cav1 ${ }^{-1-}$ hepatocytes, transactivation of the EGFR pathway by TGF$\beta$ is reduced, which correlates with the lack of activation of TACE/ADAM17; (2) the restitution of Cav1 in Cav1-/hepatocytes recapitulates wild-type phenotype features both in terms of EGFR transactivation and TACE/ADAM17 activation; (3) TACE/ADAM17 localizes to DRMs; (4) the localization of TACE/ADAM17 in DRMs increases in response to TGF- $\beta$ only in the presence of Cav1. TGF- $\beta$-dependent ERK1/2 and AKT phosphorylation was decreased in Cav1 $1^{-1-}$ cells, although extracellular EGFR ligand-dependent ERKs and AKT phosphorylation was even increased in Cav1 ${ }^{-1-}$ cells. Furthermore, basal expression of EGFR ligands is not lower in Cav1 ${ }^{-1}$ cells. This corroborates and strengthens our conclusion that it is the TACE/ADAM17dependent EGFR ligand shedding what is highly sensitive to Cav1 expression.

In support of the hypothesis that Cav1 is required for TACE/ADAM17 activation, it was suggested that its activity could be regulated by cholesterol in the plasma membrane. ${ }^{25}$ Our results after treatment with cholesterol scavengers $(\mathrm{M} \beta \mathrm{C}$, filipin III or nystatin), confirm this hypothesis and therefore are demonstrative that the integrity of lipid rafts is indeed necessary for TACE/ADAM17 activity. However, lipid raft-independent functions for TACE/ADAM17 have been also proposed. ${ }^{26}$ The requirement of cholesterol-rich domains for TACE/ADAM17 function could be cell type dependent and/or it could depend on the protein substrate.

Another important indirect conclusion of our study is that Cav1 is not required for the mitogenic response of hepatocytes to EGFR ligands such as EGF, TGF- $\alpha$ or HB-EGF. Pioneer studies in the nineties suggested that a cross talk between the EGFR and caveolins could govern EGFR signals. Activation of the EGFR was localized in non-caveolar membrane domains. ${ }^{27}$ However, EGFRs are initially concentrated in caveolae and rapidly move out of this membrane domain in response to EGFR ligands. ${ }^{28}$ Caveolin was proposed to be an inhibitor of the kinase domain of the EGFR, thus impairing its signaling. ${ }^{29}$ Caveolae do not appear to be involved in the endocytosis of EGF, which is mostly clathrin dependent, ${ }^{30}$ although recent works suggest that it could be also internalized by other pathways. ${ }^{31}$ Sustained evidence suggests that EGF stimulates the caveolae/raft-dependent endocytic pathway, which has been proposed to have relevant consequences on other cellular signals. ${ }^{14,32}$ In human tumor cells, EGFR-mediated caveolae-dependent endocytosis disrupts cell-cell adhesion and causes EMT due to E-cadherin endocytosis ${ }^{33}$ and regulates integrin-mediated cell behavior through internalization and segregation into different intracellular compartments of integrins. ${ }^{34}$ The results presented in this study suggest that cell responses to EGFR ligands in terms of receptor phosphorylation, cell proliferation and survival are Cav1 independent in hepatocytes. However, further work is required for a detailed analysis of the role of Cav1 on other cell responses related to the pro-tumorigenic effects of the EGFR pathway and that will require the use of liver tumor cells in the study.

Although the role of Cav1 in cancer is controversial, its status has been proposed to be one of the causative factors for the invasion and poor prognosis of liver tumors, in particular hepatocellular carcinoma (HCC). ${ }^{35,36}$ Overexpression of Cav1 is observed along HCC progression and could contribute to promote tumor growth and metastatic potential, through increase in tumor cell motility and invasiveness. ${ }^{36}$ Interestingly, well differentiated cell lines exhibit low and TGF- $\beta$-inducible Cav1 protein levels, whereas poorly differentiated and highly invasive HCC cell lines show high 

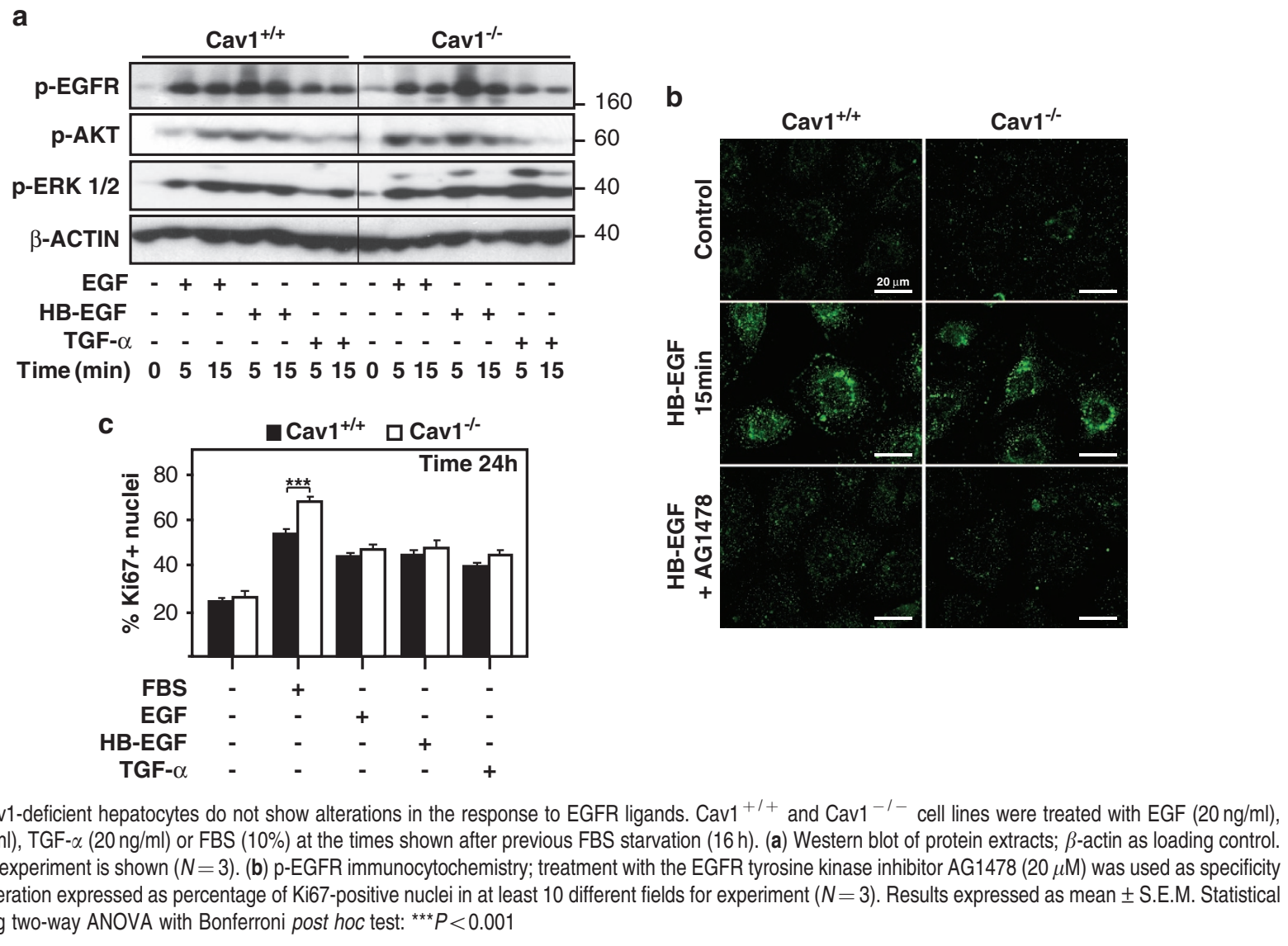

Figure 5 Cav1-deficient hepatocytes do not show alterations in the response to EGFR ligands. Cav1 ${ }^{+/+}$and Cav1 ${ }^{-/-}$cell lines were treated with EGF (20 ng/ml), HB-EGF (20 ng/ml), TGF- $\alpha(20 \mathrm{ng} / \mathrm{ml})$ or FBS $(10 \%)$ at the times shown after previous FBS starvation (16 h). (a) Western blot of protein extracts; $\beta$-actin as loading control. A representative experiment is shown $(N=3)$. (b) p-EGFR immunocytochemistry; treatment with the EGFR tyrosine kinase inhibitor AG1478 (20 $\mu$ M) was used as specificity control. (c) Proliferation expressed as percentage of Ki67-positive nuclei in at least 10 different fields for experiment $(N=3)$. Results expressed as mean \pm S.E.M. Statistical comparison using two-way ANOVA with Bonferroni post hoc test: ${ }^{* \star} P<0.001$
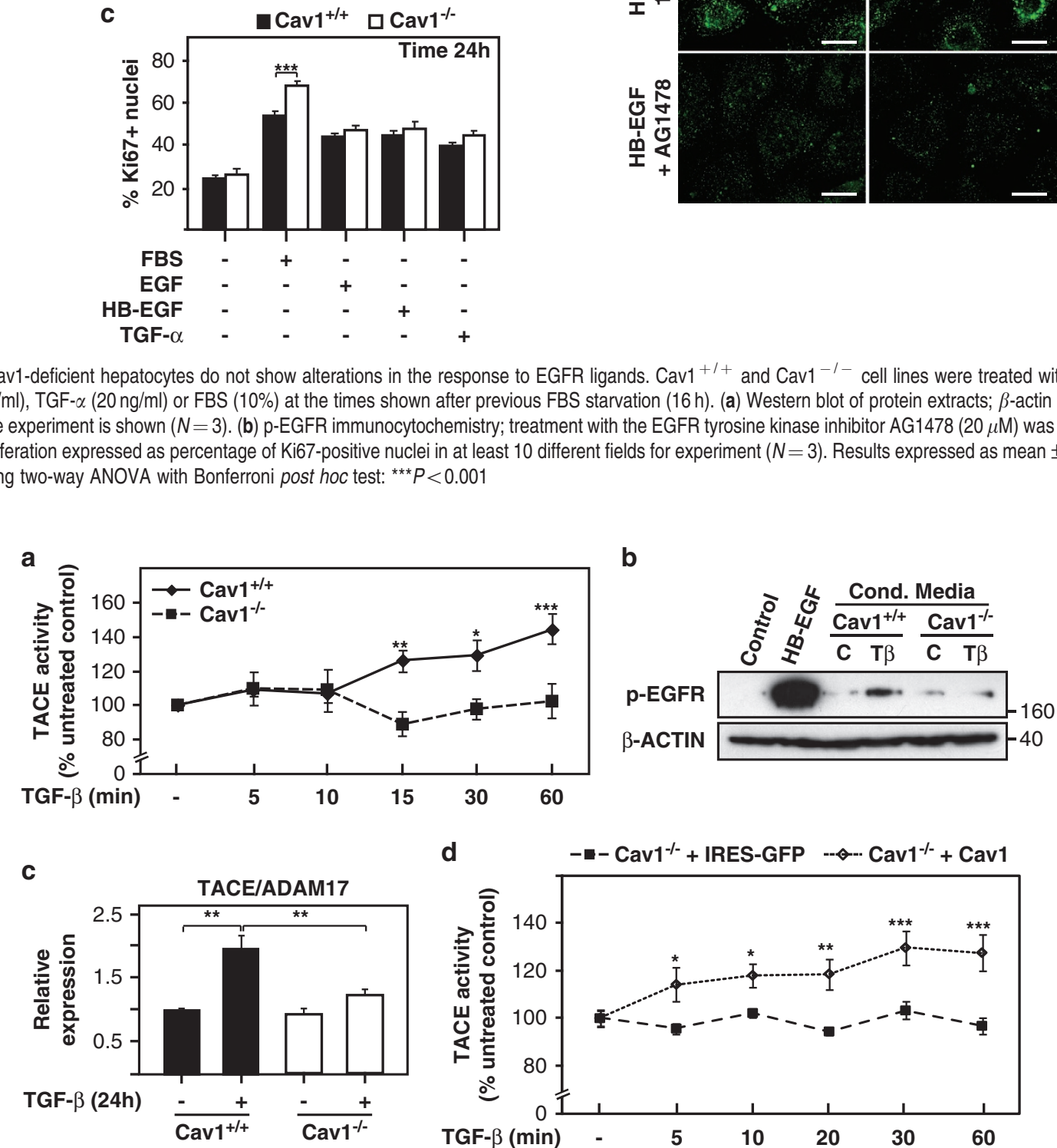
(20)

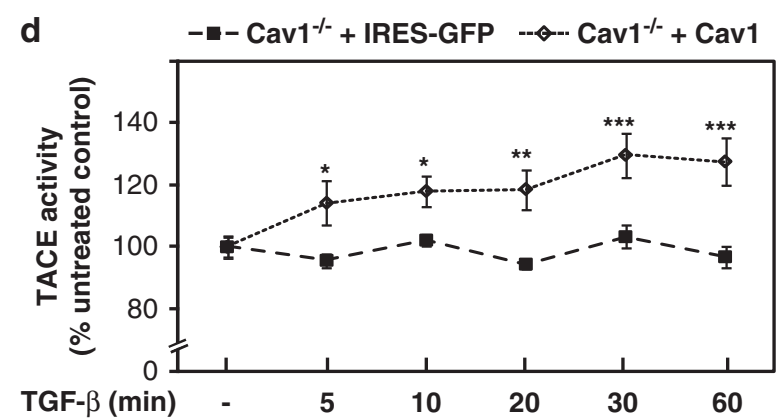

Figure 6 Cav1 deficiency prevents TGF- $\beta$-mediated TACE/ADAM17 activity in hepatocytes. (a-c) Cav1 ${ }^{+1+}$ and Cav1 ${ }^{-1-}$ hepatocytes were treated with TGF- $\beta$ $(2 \mathrm{ng} / \mathrm{ml})$ at the times shown, after previous FBS starvation (16 h). (a) Metalloprotease TACE/ADAM17 activity expressed as percentage of activity of treated versus untreated cells $(N=3)$. (b) Western blot of protein extracts from Cav1 ${ }^{+1+}$ cells; $\beta$-actin as loading control. HB-EGF $(20 \mathrm{ng} / \mathrm{ml})$ is used as a positive control of EGFR phosphorylation. Conditioned media (cond. media) from either Cav1 ${ }^{+1+}$ or Cav1 ${ }^{-1-}$ hepatocytes were collected after FBS starvation during $72 \mathrm{~h}$ in control (C) or TGF- $\beta$-treated cells (T $\beta$ ). (c) TACE/ADAM17 relative expression measured by quantitative PCR $(N=3)$. (d) Cav1 ${ }^{-1-}+$ IRES-GFP and Cav1 ${ }^{-1-}+$ Cav1 hepatocytes were used to analyze TACE/ ADAM17 activity (expressed as percentage of treated versus untreated cells, $N=3$ ) in response to TGF- $\beta$, under the treatment conditions described above. Results expressed as mean \pm S.E.M. Statistical comparison using Student's $t$-test to compare control versus $24-h$ TGF- $\beta$ treatment in each cell line (c) or two-way ANOVA with Bonferroni post hoc test to compare Cav1 ${ }^{+/+}$and Cav1 ${ }^{-l-}$ hepatocytes (a and d): ${ }^{*} P<0.05 ;{ }^{* \star} P<0.01 ;{ }^{* \star *} P<0.001$ 

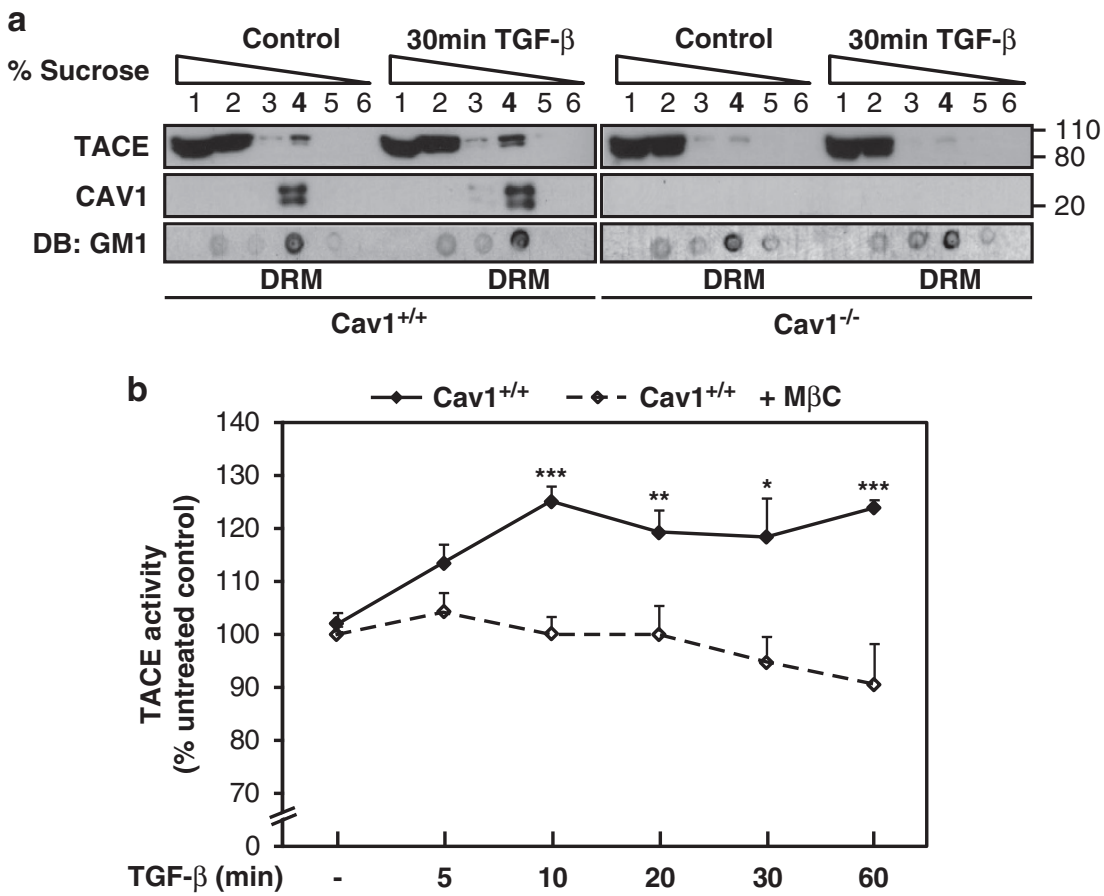

Figure 7 TACE/ADAM17 localization in lipid rafts is necessary for its TGF- $\beta$-mediated activation. Cav1 ${ }^{+1+}$ and Cav $1^{-1-}$ cell lines were treated with TGF- $\beta$ ( 2 ng/ml) at different times after previous FBS starvation ( $16 \mathrm{~h}$ ). (a) Western blot of subcellular fractions from Cav1 ${ }^{+/+}$and Cav1 ${ }^{-1-}$ cells obtained using a sucrose gradient, ganglioside M1 (GM1) used as a DRM fraction marker. DRMs are marked in bold numbers. DB = dot blot. A representative experiment is shown $(N=3)$. (b) Metalloprotease TACE/ ADAM17 activity expressed as percentage of activity/untreated control $(N=3)$. Cells were treated with M $\beta$ C 30 min before TGF- $\beta$ treatment in order to disrupt lipid rafts by removing cholesterol from membranes. Results expressed as mean \pm S.E.M. Statistical comparison using two-way ANOVA with Bonferroni post hoc test: ${ }^{\star} P<0.05$; ${ }^{* *} P<0.01 ;{ }^{* *} P<0.001$

Cav1 expression. ${ }^{37}$ Poorly differentiated HCC cells show autocrine production of TGF- $\beta$, which is responsible for its migratory and invasive capacity. ${ }^{38}$ The results presented in this manuscript suggest that high expression of Cav1 in liver tumor cells would switch the response to TGF- $\beta$ from a suppressor to a tumorigenic factor. Indeed, Cav1/lipid rafts are required for the activation of TACE/ADAM17 by TGF- $\beta$, which in turn activates the EGFR, whose signal transduction pathways compensate its anti-mitogenic and pro-apoptotic signals, allowing cells to respond to its pro-tumorigenic effects. ${ }^{4,18,39}$ We previously reported that TACE/ADAM17 activation is a requirement for TGF- $\beta$-induced transactivation of the EGFR in hepatocytes. Although TGF- $\beta$ induces TGF- $\alpha$ and HB-EGF in adult rat hepatocytes, they show a poor response to this cytokine in terms of EGFR transactivation because expression of TACE/ADAM17 is very low in these cells and the shedding/activation of the EGFR ligands is prevented. In contrast, liver tumor cells express high levels of TACE/ADAM17 and show higher capacity to transactivate the EGFR pathway in response to TGF- $\beta .{ }^{40}$ Due to this differential response, TGF- $\beta$ is a suppressor factor for adult quiescent hepatocytes, but not for hepatoma cells, where it plays a dual role, both suppressing and promoting carcinogenesis. Importantly, inhibition of TACE/ADAM17 in fetal hepatocytes or in hepatoma cells switch the TGF- $\beta$ function toward apoptosis and growth suppression. ${ }^{4,40}$ As TACE/ADAM17 is also required for TGF- $\beta$-induced growth/survival signals in breast cancer ${ }^{41,42}$ or gastric cancer ${ }^{43}$ cells, as well as for promotion of motility and invasiveness by TGF- $\beta$ in glioma cells, ${ }^{44}$ the mechanism described in this work could have transcendence in the pro-tumorigenic effects that TGF- $\beta$ exerts in many other tumors.

\section{Materials and Methods}

Reagents and antibodies. Human recombinant TGF- $\beta 1$ and AG1478 were from Calbiochem (La Jolla, CA, USA). EGF was kindly gifted by Serono Lab (Madrid, Spain). Human recombinant HB-EGF, human recombinant TGF- $\alpha, \mathrm{M} \beta \mathrm{C}$, filipin III from Streptomyces filipinensis, nystatin and water-soluble cholesterol were from Sigma-Aldrich (St. Louis, MO, USA). The antibodies used were: mouse anti- $\beta$-actin (clone AC-15) from Sigma-Aldrich, rabbit anti-phospho-Akt (Ser473) (D9E) XP, rabbit anti-Akt, rabbit anti-phospho-EGFR (Tyr1068) (D7A5) XP, rabbit anti-EGFR, rabbit anti-phospho-p44/42 MAPK (Thr202/Tyr204), rabbit anti-p44/42 MAPK were from Cell Signaling Technology (Beverly, MA, USA), mouse antiCaveolin-1 from BD Biosciences (Franklin Lakes, NJ, USA), rabbit anti-Ki67 from AbCam (Cambridge, UK), rabbit anti-TACE/ADAM17 (807-823) from Calbiochem, rabbit anti-NF $\kappa \mathrm{B}$ p65, rabbit anti-T $\beta \mathrm{RI}(\mathrm{H}-100$, used in immunocytochemistry), rabbit anti-T $\beta \mathrm{RI}(\mathrm{R}-20$, used in western blot) and rabbit anti-T $\beta \mathrm{RII}$ (C-16) from Santa Cruz Biotechnologies (Dallas, TX, USA). Secondary antibodies: Alexa Fluor 488-conjugated anti-rabbit and anti-mouse from Molecular Probes (Eugene, OR, USA) and ECL Mouse IgG, and Rabbit IgG, HRP-Linked antibodies from GE Healthcare (Buckinghamshire, UK). GM1 was detected with horseradish peroxidase-tagged cholera toxin B subunit from Sigma (St. Louis, MO, USA).

Cell culture conditions. Immortalized neonatal hepatocytes from wild type $\left(\right.$ Cav1 $\left.{ }^{+l+}\right)$ and caveolin-1 knockout $\left(\right.$ Cav1 $\left.{ }^{-l-}\right)$ mice were kindly provided by Paloma Martín-Sanz (IIBM Alberto Sols, Madrid, Spain). Isolation and immortalization of neonatal hepatocytes from Cav1 ${ }^{+1+}$ and $\mathrm{Cav}^{-1-}$ mice has been previously described. ${ }^{16,45,46}$ In order to validate our experimental model, we confirmed that Cav1 knockout cell line does not express Cav1 (Supplementary Figures 1a and d). We also tested that both cell lines showed no differences in the expression of the TGF- $\beta$ receptors type 1 and 2 (Supplementary Figures $1 b-d$ ). 
Reconstitution of $\mathrm{Cav1}^{-1-}$ cell line (Cav1 ${ }^{-1-}+$ IRES-GFP and Cav1 $1^{-1-}$ + Cav1) was kindly performed in Miguel A. del Pozo Lab (CNIC, Madrid, Spain) as previously described ${ }^{47}$ For cell culture, cells were grown in DMEM from Lonza (Basel, Switzerland), supplemented with $10 \%$ fetal bovine serum (FBS), penicillin $(120 \mu \mathrm{g} / \mathrm{ml})$, streptomycin $(100 \mu \mathrm{g} / \mathrm{ml})$ and amfoterycin B $(2.5 \mu \mathrm{g} / \mathrm{ml})$ and maintained in a humidified atmosphere of $37^{\circ} \mathrm{C}, 5 \% \mathrm{CO}_{2}$. For experiments, cells at $60 \%$ confluence were serum-starved for $16 \mathrm{~h}$ and treated with different factors: TGF- $\beta 1(2 \mathrm{ng} / \mathrm{ml})$, EGF $(20 \mathrm{ng} / \mathrm{ml})$, HB-EGF $(20 \mathrm{ng} / \mathrm{ml})$ and TGF- $\alpha(20 \mathrm{ng} / \mathrm{ml})$. When indicated, the following products were added $30 \mathrm{~min}$ before the other factors (TGF- $\beta 1$ or HB-EGF) and maintained along the experiment: AG1478 $(20 \mu \mathrm{M})$, $\mathrm{M} \beta \mathrm{C}(2.5 \mu \mathrm{M})$, filipin III $(0.5 \mu \mathrm{M})$ and nystatin $(25 \mu \mathrm{M})$. For reversion of the $\mathrm{M} \beta \mathrm{C}$ effect by treatment of cells with extracellular cholesterol $(1 \mathrm{mM})$, this lipid was added after 30 -min treatment with $\mathrm{M} \beta \mathrm{C}$, waiting for an additional $1 \mathrm{~h}$ before adding TGF- $\beta 1$, and maintained along the experiment.

Analysis of cell viability. Cell viability was analyzed using both trypan blue and propidium iodide (PI). For trypan blue dye cells were trypsinized collecting the media. After 5-min centrifugation at 1200 r.p.m., cells were resuspended in $50 \mu \mathrm{l}$ PBS $+1: 10 \mathrm{v} / \mathrm{v}$ trypan blue. Viable and non-viable (blue dyed) cells were counted in a Neubauer chamber, counting eight squares for condition, with duplicates. Results are expressed as percentage of viable and non-viable cells. For PI staining, $1 \mu \mathrm{g} / \mathrm{ml}$ (final concentration) PI from Sigma-Aldrich was added to each well (from a 12-well multiwell plate). Afterward, PI-positive cells were counted in a phase contrast microscope Olympus IX70 (Tokyo, Japan). Results were expressed as percentage of PI-positive cells.

Measurement of intracellular redox state. The oxidation-sensitive fluorescent probe $2^{\prime}, 7^{\prime}$-dichlorodihydrofluorescein diacetate $\left(\mathrm{H}_{2} \mathrm{DCFDA}\right.$; from Invitrogen, Carlsbad, CA, USA) was used to analyze the total intracellular content of ROS as previously described. ${ }^{39}$ Fluorescence was measured in a Microplate Fluorescence Reader Fluostar Optima (BMG LABTECH, Ortenberg, Germany) and expressed as percentage of control after correction with protein content.

Analysis of caspase- 3 activity. Fluorimetric analysis of caspase- 3 activity was determined as described previously, ${ }^{4}$ using the Caspase-3 fluorogenic substrate Ac-DEVD-AMC from BD Pharmingen (Franklin Lakes, NJ, USA), with $20 \mu \mathrm{g}$ of protein extract. Protein concentration of cell lysates was determined using Bradford Reagent from Sigma-Aldrich. A unit of caspase-3 activity is the amount of active enzyme necessary to produce an increase in 1 fluorescence unit and results are presented as units of caspase- 3 activity $/ \mathrm{h} / \mu \mathrm{g}$ protein.

Western blot analysis. Total protein extracts and western blot procedure were carried out as previously described. ${ }^{5,39}$ Primary antibodies were used at $1: 1000$, except $\beta$-actin $(1: 5000)$, secondary antibodies were used at $1: 5000$. Protein concentration was measured with BCA Protein Assay kit (Pierce, Rockford, USA). Densitometric analysis of protein bands intensity was performed using ImageJ software (Public domain, NIH, Bethesda, MD, USA).

Dot blot analysis. A 2- $\mu$ l drop of protein extract is applied onto nitrocellulose membrane and let to dry during $6-8 \mathrm{~h}$. The following procedure is the same as for western blot analysis.

Immunocytochemistry studies. Fluorescence microscopy studies were performed as described previously. ${ }^{40}$ Cells were fixed with $4 \%$ paraformaldehyde in PBS for 20 min at RT for NF $\kappa$ B-p65 and Ki67 stainings and with methanol for $2 \mathrm{~min}$ at $-20^{\circ} \mathrm{C}$ for phospho-EGFR, T $\beta \mathrm{RI}, \mathrm{T} \beta \mathrm{RII}$ and caveolin- 1 stainings. Coverslips were then incubated with primary antibody diluted in $1 \% \mathrm{BSA}$ for $2 \mathrm{~h}$ at $\mathrm{RT}$ for NF $\kappa \mathrm{B}-\mathrm{p} 65$ and $\mathrm{Ki} 67$ or overnight at $4{ }^{\circ} \mathrm{C}$ for all other antibodies (dilutions: NF $\kappa$ B-p65 1:50; Ki67 1:100; p-EGFR 1:200; T $\beta$ RI 1:200, T $\beta$ RII 1:200 and caveolin-1 1:200). After several washes with PBS, the samples were incubated with Alexa Fluor 488-conjugated anti-rabbit or anti-mouse for $1 \mathrm{~h}$ at $\mathrm{RT}(1: 200)$. After washing with PBS, nuclear DNA was stained with DAPI (Sigma-Aldrich) and samples were mounted in MOWIOL 4-88 reagent (Calbiochem). Cells were visualized in a Nikon-80I microscope (Tokyo, Japan) with the appropriate filters, except in the Supplementary Figure 1, where an Olympus BX-60 microscope (Tokyo, Japan) and a Leica TCS-NT confocal microscope (Wetzlar, Germany) were used (as specified in its figure legend). Representative images were taken and edited in Adobe Photoshop software.
TACE/ADAM17 activity measurement. Fluorimetric measurement of TACE/ADAM17 activity was determined as described previously, ${ }^{4}$ using $10 \mu \mathrm{M}$ TACE Substrate IV from Calbiochem, with $10 \mu \mathrm{g}$ of protein extract. Fluorescence was measured in a Microplate Fluorescence Reader Fluostar Optima every 5 min during $1 \mathrm{~h}$ at $37^{\circ} \mathrm{C}$ (excitation: $320 \mathrm{~nm}$; emission: $420 \mathrm{~nm}$ ). Protein concentration of cell lysates was determined using Bradford reagent from Sigma-Aldrich. Results were expressed as percentage of activity compared with the untreated control $(100 \%)$

Analysis of gene expression. RNeasy Mini Kit (Qiagen, Valencia, CA, USA) was used for total RNA isolation. Reverse transcription (RT) was carried out using the High Capacity Reverse Transcriptase kit (Applied Biosystems, Foster City, CA, USA), with $500 \mathrm{ng}$ of total RNA from each sample for complementary DNA synthesis.

For real-time quantitative PCR, expression levels were determined in duplicate in an ABIPrism7700 System, using the Sybr Green PCR Master Mix (Applied Biosystems) or in a LightCycler 480 System, using LightCycler 480 SYBR Green I Master Mix (Roche, Basel, Switzerland). Reactions were performed with the following mouse-specific primers:

\begin{tabular}{|c|c|}
\hline TACE/ & 5'-GGGTTTTGCGACATGAATGG-3' forward \\
\hline & 5'-GAAAACCAGAACAGACCCAAC-3' reverse \\
\hline EGFR & $\begin{array}{l}\text { 5'-CTCCATGCTTTCGAGAACCTAG-3' forward } \\
5^{\prime} \text {-ATGATCACATCCCCATCACTG-3' reverse }\end{array}$ \\
\hline$T \beta R I$ & 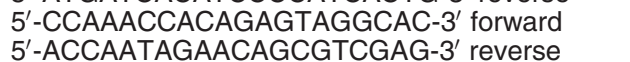 \\
\hline$T \beta R I I$ & $\begin{array}{l}5^{\prime} \text {-GGAGAAGTGAAGGATTACGAGC-3' forward } \\
5^{\prime} \text {-CACACGATCTGGATGCCC- } 3^{\prime} \text { reverse }\end{array}$ \\
\hline$H B-E G F$ & $\begin{array}{l}5^{\prime} \text {-CCCCTATACACATATGACCACAC- } 3^{\prime} \text { forward } \\
5^{\prime} \text {-CAACTTCACTTTCTCTTCACTTTCC- } 3^{\prime} \text { reverse }\end{array}$ \\
\hline$T G F$ & $\begin{array}{l}5^{\prime} \text {-CTGGGTATCCTGTTAGCTGTG-3' } 3^{\prime} \text { forward } \\
5^{\prime} \text {-GTACTGAGTGTGGGAATCTGG-3' reverse }\end{array}$ \\
\hline AREG & $\begin{array}{l}5^{\prime} \text {-AGATACATCGAGAACCTGGAGG- } 3^{\prime} \text { forward } \\
5^{\prime} \text {-AGAGACAAAGATAGTGACAGCTAC-3' reverse }\end{array}$ \\
\hline L32 & $\begin{array}{l}\text { 5'-ACAATGTCAAGGAGCTGGAG-3' forward } \\
\text { 5'-TTGGGATTGGTGACTCTGATG-3' reverse }\end{array}$ \\
\hline $18 S$ & $\begin{array}{l}5^{\prime} \text {-CGAGACTCTGGCATGCTAA-3' forward } \\
5^{\prime} \text {-CGCCACTTGTCCCTCTAAG-3' reverse }\end{array}$ \\
\hline
\end{tabular}

Knockdown assays. For transient siRNA transfection, cells were transfected at $50 \%$ confluence using TransIT-siQuest (Mirus, Madison, WI, USA) at 1:300 dilution in complete medium, according to the manufacturer's recommendation, with a final siRNA concentration of $50 \mathrm{nM}$ during $8 \mathrm{~h}$. Oligos were obtained from Sigma-Genosys (Suffolk, UK). The oligo sequences were as follows:

Unsilencing $5^{\prime}$-GUAAGACACGACUUA UCGC-3'

Cav1(1) 5'-ACGUAGACUCCGAGGGACA-3'

Cav1(2) 5'-GCAAAUACGUAGACUCCGA-3'

EGFR 5'-GCGAUAAGUCGUGUCUUAC-3'

The unsilencing siRNA used was selected from previous works. ${ }^{39}$

Preparation of detergent-resistant membrane (DRM) fractions. DRM fractions were purified as described in Navarro-Lerida et al. ${ }^{48}$ Two confluent p100 plates were scraped from each cell line and resuspended in $335 \mu \mathrm{l}$ (final volume) MES-buffered saline (MBS: $25 \mathrm{mM}$ MES, pH 6.5, $0.15 \mathrm{M} \mathrm{NaCl}, 1 \mathrm{mM}$ PMSF plus $1 \%$ Triton $\mathrm{X}-100$ ) at $4{ }^{\circ} \mathrm{C}$. Cells were homogenized by a minimum of 10 strokes through a syringe $(0.5 \times 16 \mathrm{~mm})$ on ice. The homogenate was brought up to $670 \mu \mathrm{l}$ by adding $335 \mu \mathrm{l} 80 \%$ sucrose in MBS, and placed at the bottom of a Beckman TLS-55 2.2 ml Ultraclear tube (Beckman Coulter, Brea, CA, USA). The discontinuous sucrose gradient $(40-30-5 \%)$ was formed by sequentially loading $670 \mu \mathrm{l} 30 \%$ sucrose and $670 \mu \mathrm{l} \%$ sucrose in MBS. Separation was performed by centrifuging at 50000 r.p.m. for $3 \mathrm{~h}$ in a TLS-55 rotor (Beckman Coulter) at $4{ }^{\circ} \mathrm{C}$ (using an Optima MAX-TL ultracentrifuge, Beckman Coulter). A light, scattered band confined to the $5-30 \%$ sucrose interface was observed that contained most caveolin-1 protein and excluded most other proteins. Six $335-\mu$ l fractions were collected, starting from the bottom of the tube. An equal volume of cold acetone was added to each fraction and the proteins precipitated overnight at $4{ }^{\circ} \mathrm{C}$. Protein pellets were collected by centrifugation at 13000 r.p.m. and air-dried for $2 \mathrm{~h}$ to 
eliminate acetone traces. The protein precipitates were then analyzed by SDSPAGE and western blot, or dot blot in the case of GM1.

Statistics. All data represents at least three experiments and are expressed as the mean \pm S.E.M. Differences between groups were compared using Student's t-test (when comparing two groups), one-way ANOVA with Tukey's multiple comparison test (when comparing more than two groups and considering one independent variable) or two-way ANOVA with Bonferroni post hoc test (when comparing differences between groups considering two independent variables). All statistical tests were conducted using GraphPad Prism (La Jolla, CA, USA). Differences were considered statistically significant at ${ }^{*} P<0.05$, ${ }^{* \star} P<0.01$ and ${ }^{* \star *} P<0.001$.

\section{Conflict of Interest}

The authors declare no conflict of interest.

Acknowledgements. This work was supported by grants from: (1) the Ministry of Economy and Competitiveness (MINECO), Spain (BFU2012-35538 and ISCIII-RTICC: RD12-0036-0029 to IF; SAF2013-43713 to PM-S; BFU2012-33932 to GE; SAF2011-25047 and CSD2009-00016 to MAdP); (2) AGAUR-Generalitat de Catalunya (2009SGR-312 to IF); and (3) People Programme (Marie Curie Actions) of the European Union's Seventh Framework Programme (FP7/2007-2013) under REA grant agreement no. PITN-GA-2012-316549 (IT LIVER) to IF JM-C and RM-V were recipients of pre-doctoral fellowships from the FPU program (Ministry of Education, Culture and Sport, Spain) and the FPI program (associated to SAF201125047, MINECO, Spain), respectively. We acknowledge the review and suggestions of Dr. Christoph Meyer (University of Heidelberg, Mannheim, Germany).

1. Massague J. TGFbeta in cancer. Cell 2008; 134: 215-230.

2. Valdes F, Murillo MM, Valverde AM, Herrera B, Sanchez A, Benito M et al. Transforming growth factor-beta activates both pro-apoptotic and survival signals in fetal rat hepatocytes. Exp Cell Res 2004; 292: 209-218.

3. Valdes F, Alvarez AM, Locascio A, Vega S, Herrera B, Fernandez M et al. The epithelial mesenchymal transition confers resistance to the apoptotic effects of transforming growth factor Beta in fetal rat hepatocytes. Mol Cancer Res 2002; 1: 68-78.

4. Murillo MM, del Castillo G, Sanchez A, Fernandez M, Fabregat I. Involvement of EGF receptor and c-Src in the survival signals induced by TGF-beta1 in hepatocytes. Oncogene 2005; 24: 4580-4587.

5. Murillo MM, Carmona-Cuenca I, Del Castillo G, Ortiz C, Roncero C, Sanchez A et al. Activation of NADPH oxidase by transforming growth factor-beta in hepatocytes mediates up-regulation of epidermal growth factor receptor ligands through a nuclear factor-kappaBdependent mechanism. Biochem J 2007; 405: 251-259.

6. Le Roy C, Wrana JL. Clathrin- and non-clathrin-mediated endocytic regulation of cell signalling. Nat Rev Mol Cell Biol 2005; 6: 112-126.

7. Chen YG. Endocytic regulation of TGF-beta signaling. Cell Res 2009; 19: 58-70.

8. Di Guglielmo GM, Le Roy C, Goodfellow AF, Wrana JL. Distinct endocytic pathways regulate TGF-beta receptor signalling and turnover. Nat Cell Biol 2003; 5: 410-421.

9. Meyer C, Liu Y, Dooley S. Caveolin and TGF-beta entanglements. J Cell Physiol 2013; 228: 2097-2102.

10. Meyer C, Godoy P, Bachmann A, Liu Y, Barzan D, Ilkavets I et al. Distinct role of endocytosis for Smad and non-Smad TGF-beta signaling regulation in hepatocytes. J Hepatol 2011; 55: 369-378.

11. Meyer C, Liu Y, Kaul A, Peipe I, Dooley S. Caveolin-1 abrogates TGF-beta mediated hepatocyte apoptosis. Cell Death Dis 2013; 4: e466.

12. Fernandez-Rojo MA, Restall C, Ferguson C, Martel N, Martin S, Bosch M et al. Caveolin-1 orchestrates the balance between glucose and lipid-dependent energy metabolism: implications for liver regeneration. Hepatology 2012; 55: 1574-1584.

13. Wang $\mathrm{Y}$, Posner BI, Balbis A. Compartmentalization of epidermal growth factor receptor in liver plasma membrane. J Cell Biochem 2009; 107: 96-103.

14. Pol A, Lu A, Pons M, Peiro S, Enrich C. Epidermal growth factor-mediated caveolin recruitment to early endosomes and MAPK activation. Role of cholesterol and actin cytoskeleton. J Biol Chem 2000; 275: 30566-30572.

15. Park JH, Han HJ. Caveolin-1 plays important role in EGF-induced migration and proliferation of mouse embryonic stem cells: involvement of PI3K/Akt and ERK. Am J Physiol Cell Physiol 2009; 297: C935-C944.

16. Mayoral R, Valverde AM, Llorente Izquierdo C, Gonzalez-Rodriguez A, Bosca L, MartinSanz P. Impairment of transforming growth factor beta signaling in caveolin-1-deficient hepatocytes: role in liver regeneration. J Biol Chem 2010; 285: 3633-3642.
17. Carmona-Cuenca I, Roncero C, Sancho P, Caja L, Fausto N, Fernandez M et al. Upregulation of the NADPH oxidase NOX4 by TGF-beta in hepatocytes is required for its pro-apoptotic activity. J Hepatol 2008; 49: 965-976.

18. Caja L, Sancho P, Bertran E, Fabregat I. Dissecting the effect of targeting the epidermal growth factor receptor on TGF-beta-induced-apoptosis in human hepatocellular carcinoma cells. J Hepatol 2011; 55: 351-358.

19. Takaguri A, Shirai H, Kimura K, Hinoki A, Eguchi K, Carlile-Klusacek M et al. Caveolin-1 negatively regulates a metalloprotease-dependent epidermal growth factor receptor transactivation by angiotensin II. J Mol Cell Cardiol 2011; 50: 545-551.

20. D'Alessio A, Esposito B, Giampietri C, Ziparo E, Pober JS, Filippini A. Plasma membrane microdomains regulate TACE-dependent TNFR1 shedding in human endothelial cells. J Cell Mol Med 2012; 16: 627-636.

21. Xu P, Liu J, Derynck R. Post-translational regulation of TGF-beta receptor and Smad signaling. FEBS Lett 2012; 586: 1871-1884.

22. Massague J. TGFbeta signalling in context. Nat Rev Mol Cell Biol 2012; 13: 616-630.

23. Vizan P, Miller DS, Gori I, Das D, Schmierer B, Hill CS. Controlling long-term signaling: receptor dynamics determine attenuation and refractory behavior of the TGF-beta pathway. Sci Signal 2013; 6: ra106.

24. Sunnarborg SW, Hinkle CL, Stevenson M, Russell WE, Raska CS, Peschon JJ et al. Tumor necrosis factor-alpha converting enzyme (TACE) regulates epidermal growth factor receptor ligand availability. J Biol Chem 2002; 277: 12838-12845.

25. Tellier E, Canault M, Poggi M, Bonardo B, Nicolay A, Alessi MC et al. HDLs activate ADAM17-dependent shedding. J Cell Physiol 2008; 214: 687-693.

26. Parr-Sturgess CA, Rushton DJ, Parkin ET. Ectodomain shedding of the Notch ligand Jagged1 is mediated by ADAM17, but is not a lipid-raft-associated event. Biochem J 2010; 432: 283-294.

27. Waugh MG, Lawson D, Hsuan JJ. Epidermal growth factor receptor activation is localized within low-buoyant density, non-caveolar membrane domains. Biochem J 1999; 337(Pt 3): 591-597.

28. Mineo C, Gill GN, Anderson RG. Regulated migration of epidermal growth factor receptor from caveolae. J Biol Chem 1999; 274: 30636-30643.

29. Couet J, Sargiacomo M, Lisanti MP. Interaction of a receptor tyrosine kinase, EGF-R, with caveolins. Caveolin binding negatively regulates tyrosine and serine/threonine kinase activities. J Biol Chem 1997; 272: 30429-30438.

30. Kazazic M, Roepstorff K, Johannessen LE, Pedersen NM, van Deurs B, Stang E et al. EGF-induced activation of the EGF receptor does not trigger mobilization of caveolae. Traffic 2006; 7: 1518-1527.

31. Henriksen L, Grandal MV, Knudsen SL, van Deurs B, Grovdal LM. Internalization mechanisms of the epidermal growth factor receptor after activation with different ligands. PLoS One 2013; 8: e58148.

32. Pol A, Calvo M, Enrich C. Isolated endosomes from quiescent rat liver contain the signal transduction machinery. Differential distribution of activated Raf- 1 and Mek in the endocytic compartment. FEBS Lett 1998; 441: 34-38.

33. Lu Z, Ghosh S, Wang Z, Hunter T. Downregulation of caveolin-1 function by EGF leads to the loss of E-cadherin, increased transcriptional activity of beta-catenin, and enhanced tumor cell invasion. Cancer Cell 2003; 4: 499-515.

34. Ning Y, Buranda T, Hudson LG. Activated epidermal growth factor receptor induces integrin alpha2 internalization via caveolae/raft-dependent endocytic pathway. J Biol Chem 2007; 282: 6380-6387.

35. Tang Y, Zeng X, He F, Liao Y, Qian N, Toi M. Caveolin-1 is related to invasion, survival, and poor prognosis in hepatocellular cancer. Med Oncol 2012; 29: 977-984.

36. Tse EY, Ko FC, Tung EK, Chan LK, Lee TK, Ngan ES et al. Caveolin-1 overexpression is associated with hepatocellular carcinoma tumourigenesis and metastasis. J Pathol 2012; 226: 645-653.

37. Meyer C, Dzieran J, Liu Y, Schindler F, Munker S, Muller A et al. Distinct dedifferentiation processes affect caveolin-1 expression in hepatocytes. Cell Commun Signal 2013; 11: 6.

38. Bertran E, Crosas-Molist E, Sancho P, Caja L, Lopez-Luque J, Navarro E et al. Overactivation of the TGF-beta pathway confers a mesenchymal-like phenotype and CXCR4-dependent migratory properties to liver tumor cells. Hepatology 2013; 58: 2032-2044.

39. Sancho P, Bertran E, Caja L, Carmona-Cuenca I, Murillo MM, Fabregat I. The inhibition of the epidermal growth factor (EGF) pathway enhances TGF-beta-induced apoptosis in rat hepatoma cells through inducing oxidative stress coincident with a change in the expression pattern of the NADPH oxidases (NOX) isoforms. Biochim Biophys Acta 2009; 1793: 253-263

40. Caja L, Ortiz C, Bertran E, Murillo MM, Miro-Obradors MJ, Palacios E et al. Differential intracellular signalling induced by TGF-beta in rat adult hepatocytes and hepatoma cells: implications in liver carcinogenesis. Cell Signal 2007; 19: 683-694.

41. Wang SE, Xiang B, Guix M, Olivares MG, Parker J, Chung CH et al. Transforming growth factor beta engages TACE and ErbB3 to activate phosphatidylinositol-3 kinase/Akt in ErbB2-overexpressing breast cancer and desensitizes cells to trastuzumab. Mol Cell Biol 2008; 28: 5605-5620.

42. Wang SE, Xiang B, Zent R, Quaranta V, Pozzi A, Arteaga CL. Transforming growth factor beta induces clustering of HER2 and integrins by activating Src-focal adhesion kinase and receptor association to the cytoskeleton. Cancer Res 2009; 69: 475-482. 
43. Ebi M, Kataoka H, Shimura T, Kubota E, Hirata Y, Mizushima T et al. TGFbeta induces proHB-EGF shedding and EGFR transactivation through ADAM activation in gastric cancer cells. Biochem Biophys Res Commun 2010; 402: 449-454.

44. Lu Y, Jiang F, Zheng X, Katakowski M, Buller B, To SS et al. TGF-beta1 promotes motility and invasiveness of glioma cells through activation of ADAM17. Oncol Rep 2011; 25 1329-1335.

45. Martin-Sanz P, Callejas NA, Casado M, Diaz-Guerra MJ, Bosca L. Expression of cyclooxygenase-2 in foetal rat hepatocytes stimulated with lipopolysaccharide and proinflammatory cytokines. Br J Pharmacol 1998; 125: 1313-1319.

46. Valverde AM, Burks DJ, Fabregat I, Fisher TL, Carretero J, White MF et al. Molecular mechanisms of insulin resistance in IRS-2-deficient hepatocytes. Diabetes 2003; 52 2239-2248.

47. Grande-Garcia A, Echarri A, de Rooij J, Alderson NB, Waterman-Storer CM, Valdivielso JM et al. Caveolin-1 regulates cell polarization and directional migration through Src kinase and Rho GTPases. J Cell Biol 2007; 177: 683-694.

48. Navarro-Lerida I, Alvarez-Barrientos A, Gavilanes F, Rodriguez-Crespo I. Distance-dependent cellular palmitoylation of de-novo-designed sequences and their translocation to plasma membrane subdomains. J Cell Sci 2002; 115 : 3119-3130.

Cell Death and Disease is an open-access journal published by Nature Publishing Group. This work is licensed under a Creative Commons Attribution-NonCommercialShareAlike 3.0 Unported License. The images or other third party material in this article are included in the article's Creative Commons license, unless indicated otherwise in the credit line; if the material is not included under the Creative Commons license, users will need to obtain permission from the license holder to reproduce the material. To view a copy of this license, visit http://creativecommons.org/ licenses/by-nc-sa/3.0/

Supplementary Information accompanies this paper on Cell Death and Disease website (http://www.nature.com/cddis) 